Brit. F. vener. Dis. (1975) 51, 310

\title{
Chlamydial infection of the male baboon urethra
}

\author{
RONALD F. DIGIACOMO, JAMES L. GALE, SAN-PIN WANG, AND \\ MARK D. KIVIAT \\ From the Departments of Epidemiology and International Health, and Pathobiology, School of Public Health and \\ Community Medicine, and the Department of Urology, School of Medicine, and the Regional Primate Research \\ Center, University of Washington, Seattle, Washington 98195, U.S.A.
}

Morbidity due to nongonococcal urethritis (NGU) has increased sharply in the last decade. In Great Britain, where incidence rates are available, NGU cases have exceeded the number of cases of gonorrhoea in men since 1965 (King, 1970; Willcox, 1972). While statistics are not generally available, there are indications that this trend is apparent in other Western countries, including the United States. Several recent studies have shown an association of NGU with Chlamydia trachomatis infection (Dunlop, Vaughan-Jackson, Darougar, and Jones, 1972; Holmes, Handsfield, Wang, Wentworth, Turck, Anderson, and Alexander, 1975; Oriel, Reeve, Powis, Miller, and Nicol, 1972; Richmond, Hilton, and Clarke, 1972). However, a causal relationship has not been definitively established. Experimental production of chlamydial urethritis in a nonhuman primate would provide strong evidence for the pathogenicity of Chlamydia in the human urogenital tract, as well as a model for study.

Nonhuman primates have been utilized as genital infection models for a variety of chlamydial agents. Female monkeys, most notably baboons (Papio sp.) and the Formosan rock macaque (Macaca cyclopis), have been used in studies of maternal chlamydial cervicitis and its associated sequela, infant inclusion conjunctivitis (Alexander and Chiang, 1967; Braley, 1939; Pukhner and Kozlova, 1965, 1967; Thygeson, 1934; Thygeson and Mengert, 1936). Inclusionpositive cervicitis has been produced in baboons, but not in macaques, although the latter shed chlamydial organisms and develop serum antibody. A chlamydial strain isolated from a case of Reiter's syndrome produced Chlamydia-positive urethral discharge 7 days after repeated intraurethral inoculations in one

Received for publication February 18, 1975

Address for reprints: Dr. R. F. DiGiacomo, School of Public Health and Community Medicine, University of Washington, Seattle, Washington 98195, U.S.A.

This study was supported by Grants AI-12192 from the National Institute of Allergy and Infectious Diseases, EY-00219 from the National Eye Institute and RR-00166 from the Division of Research Resources, National Institutes of Health of two male rhesus monkeys (Smith, James, Schachter, Engleman, and Meyer, 1973). Dunlop, Al-Hussaini, Garland, Treharne, Harper, and Jones (1965) attempted preputial infection of male baboons with a Chlamydia strain isolated from an NGU patient but no lesions developed. Darougar, Kinnison, and Jones (1971) produced inclusion-positive follicular urethritis in a male baboon with a strain of Chlamydia isolated from the rectum of a mother whose infant had TRIC ophthalmia neonatorum.

While the literature is inconclusive, it appears that of the nonhuman primates baboons may have a greater susceptibility to chlamydial infections of the genital tract. Hence the clinical, microbiological, and serological responses to urethral chlamydial infection in male baboons were investigated and are described.

\section{Material and methods}

BABOONS

Two young adult, sexually mature, male baboons (Papio cynocephalus) weighing 13-15 kg. were used.

\section{CHLAMYDIAL STRAINS}

Chlamydia trachomatis strains D/UW-102/U and I/UW$114 / \mathrm{U}$ were used. Both strains were isolated in irradiated McCoy cells from the urethra of male patients with nongonococcal urethritis seen in a venereal disease clinic in Seattle (Holmes and others, 1975). Either egg yolk sac or irradiated McCoy cell passage material was used for the urethral inoculations.

\section{URETHRAL INOCULATION}

Chlamydial organisms, suspended in $0.5 \mathrm{ml}$. of media, were inoculated through a $3 \frac{1}{2} \mathrm{FR}$ catheter inserted 2 to $4 \mathrm{~cm}$. into the urethra. The glans was compressed with the fingertips for 5 to $10 \mathrm{~min}$. and the urethra intermittently massaged to expose the entire penile urethra to the inoculum. Inoculation and the collection of specimens (urethral swabs and blood from the cephalic vein) were performed under sedation with intramuscular ketamine hydrochloride (Vetalar, Parke, Davis and Co., Detroit, Michigan). The baboons were restrained in specially built simian chairs with urine collection pans. 


\section{URINE ANALYSIS}

Labstix reagent strips (Ames Co., Elkhart, Indiana) were used for urinary protein and $\mathrm{pH}$ determinations. Aliquots of urine were centrifuged at 500 r.p.m. (45 G.) for $5 \mathrm{~min}$. and the sediment examined for leucocytes.

\section{CHLAMYDIAL ISOLATION}

Swabs from the urethra were placed in a sucrose-phosphate buffer (Gordon, Dressler, Quan, McQuillan, and Thomas, 1972) containing $50 \mu \mathrm{g}$. streptomycin and 25 units nystatin per $\mathrm{ml}$., frozen at $-70^{\circ} \mathrm{C}$, and thawed immediately before testing. Isolations were performed as previously described (Wentworth, 1973; Wentworth and Alexander, 1974) utilizing either irradiated or 5-iodo-2-deoxyuridinetreated McCoy cells. The isolates were immunotyped to confirm their origin.

\section{MICROIMMUNOFLUORESCENCE (MICRO-IF)}

An indirect FA technique described previously (Wang, 1971) was used to measure serum antibody and determine the immunotype of the isolates. Fluorescein isothiocyanate-conjugated goat antiserum to human IgM, IgG, and $\operatorname{IgA}$, obtained from Hyland Laboratories, Los Angeles, Calif., was used for detection of antibodies in baboons to twelve chlamydial immunotypes pooled into eight test antigens (Wang and Grayston, 1971a). Anti-mouse (goat) gamma globulin conjugated with fluorescein isothiocyanate, obtained from Antibodies, Inc., Davis, Calif., was used for immunotyping isolates (Wang and Grayston, 1971b).

\section{Results}

\section{Primary inoculation}

Two baboons ( 1 and 2 ) were inoculated intraurethrally with $10 \mathrm{EID}_{50}$ (50 per cent. egg infecting doses) infected yolk sac suspension of D/UW-102/U. Urethral chlamydial organisms and micro-IF antibody were absent in both baboons before inoculation. After inoculation, infection in baboon 1 was achieved as evidenced by isolation of chlamydial organisms from urethral specimens and development of micro-IF antibody. Infection did not occur in baboon 2 as both urethral isolation and micro-IF antibody were negative for 21 days after inoculation. Baboon 2 was re-inoculated with $3.5 \times 10^{3}$ inclusionforming units (IFU) of $\mathrm{D} / \mathrm{UW}-102 / \mathrm{U}$ in irradiated McCoy cells. This inoculation resulted in infection of baboon 2, established by isolation of chlamydial organisms from urethral specimens and the appearance of micro-IF antibody. The latter inoculation in baboon 2 was considered to be the primary one.

Baboons 1 and 2 shed chlamydial organisms for 96 and 90 days respectively (Figure). All isolates were Immunotype $D$, the immunotype inoculated. The intensity of the infection, roughly assessed by the number of inclusion-forming units produced by each urethral swab specimen, appeared to differ between the two baboons. During the 3 months of shedding of Chlamydia, 53 per cent. (10 of 19) of the

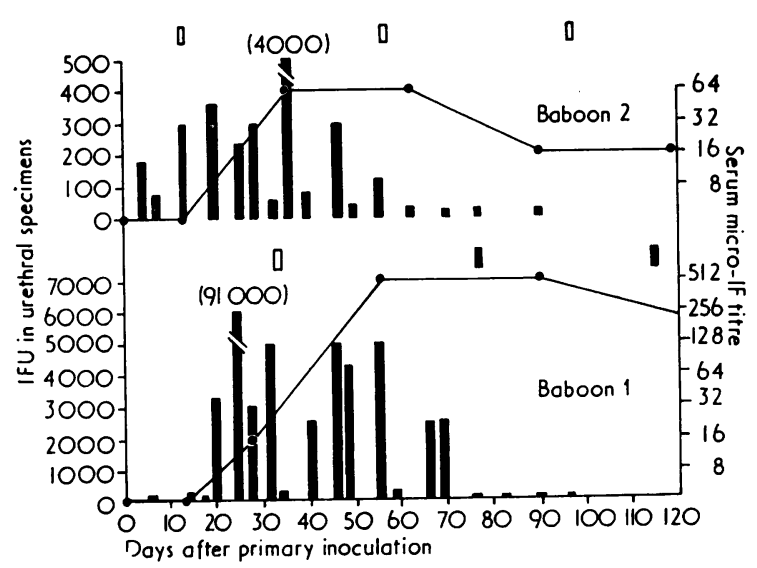

FIGURE Course of primary urethral infection of male baboons with a Type $D$ strain of $\mathrm{C}$. trachomatis. Chlamydial inclusion-forming units (IFU) in urethral specimens (histogram), reciprocal of highest serum dilution resulting in definite fluorescence in micro-IF test (line), and occurrence of urethral lesions $(\square=$ present, $\square=$ absent $)$ in baboons 1 and 2 .

urethral cultures from baboon 1 yielded 2,500 or greater IFU $/ \mathrm{ml}$., while 94 per cent. (16 of 17) of the urethral cultures from baboon 2 yielded 350 or less IFU $/ \mathrm{ml}$. (Figure). Several urine sediments were cultured, although most were unsuccessful because of bacterial contamination. A sediment positive for Chlamydia was obtained from baboon 1 on day 74 after inoculation which yielded $100 \mathrm{IFU} / \mathrm{ml}$. in culture. No chlamydial organisms were isolated from several conjunctival swab specimens. Urethral specimens, collected twice weekly, for 1 month after the 3 months of initial shedding, were consistently negative for Chlamydia.

Both baboons developed serum antibody after primary inoculation. Baboon 1 developed a micro-IF titre of $1: 16$ to Types ED 27 days after inoculation which rose to $1: 512$ at 55 days. Baboon 2 exhibited a titre of 1:64 at 35 days after inoculation which failed to rise higher thereafter (Figure). The serological response in both baboons was primarily to Types ED, a reflection of the infecting Type D strain. Baboon 1 exhibited higher homologous titres and more cross-reactions to other chlamydial antigens than did baboon 2 (Table, overleaf).

Urethroscopy, utilizing an infant panendoscope, although initially negative in both baboons, revealed vesicles in the urethral mucosa of baboon 1 at 77 and 117 days after inoculation. The vesicles were more numerous at 77 days and appeared as rounded thinwalled protuberances from the urethral surface. No other lesions were noted. Urethral lesions were not observed in baboon 2 .

No significant changes were noted in weekly 
TABLE Serum antibody response of male baboons to experimental urethral infection with Chlamydia trachomatis

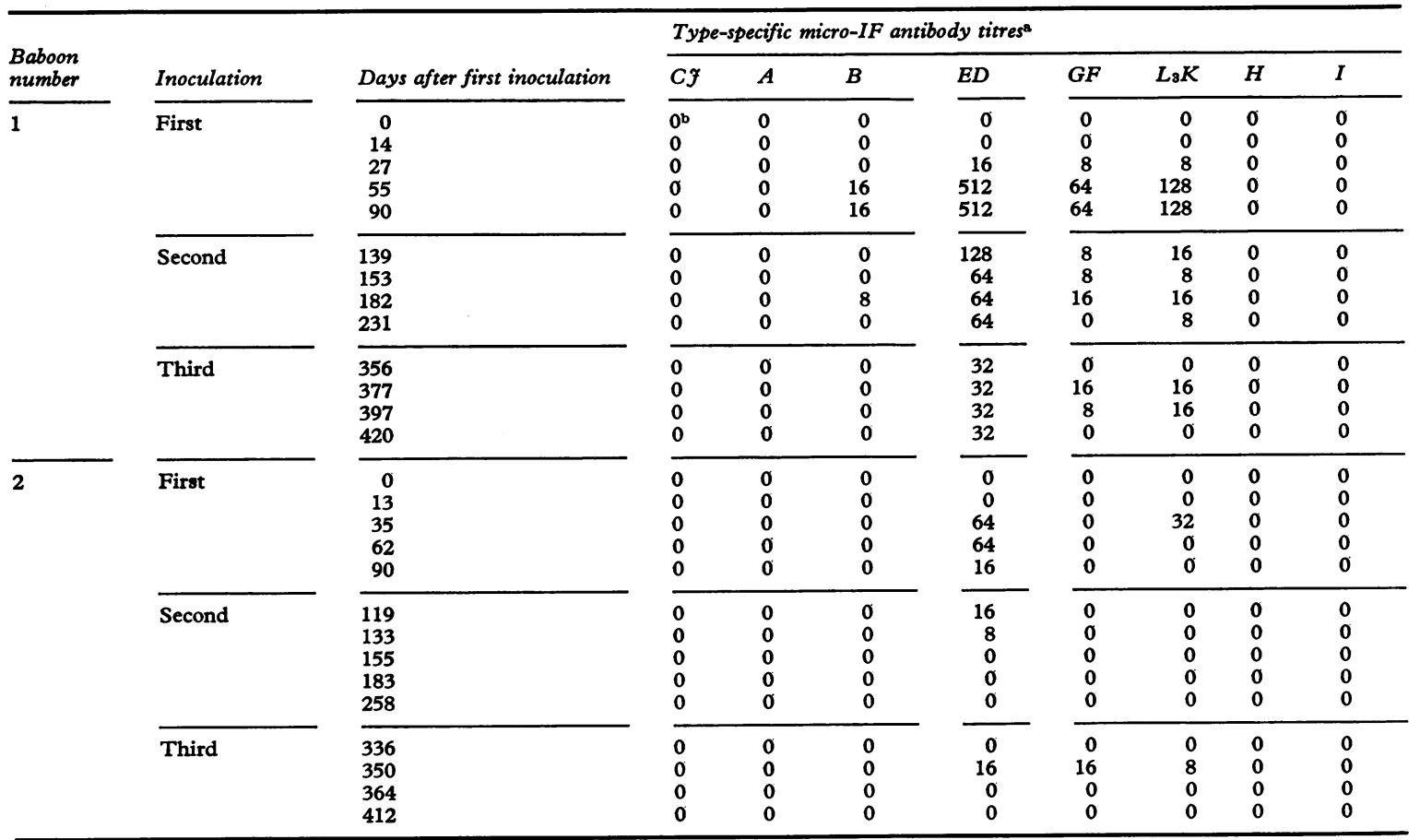

a Reciprocal of highest serum dilution resulting in definite fluorescence.

0 is less than 8 .

urinary protein and $\mathrm{pH}$ determinations; only occasionally were leucocytes observed. Spermatoza appeared in the urine sediment of both baboons. There was no clinical evidence of a urethral discharge.

\section{Second inoculation}

A second intraurethral inoculation was performed approximately 4 months after the first. Baboon 1 was inoculated with $2.5 \times 10^{4} \mathrm{IFU}$ of $\mathrm{I} / \mathrm{UW}-114 / \mathrm{U}$ strain and baboon 2 with $2.5 \times 10^{4}$ IFU of the same $\mathrm{D} / \mathrm{UW}-102 / \mathrm{U}$ strain. A single urethral specimen from baboon 2, at 3 days after inoculation was positive, yielding $10 \mathrm{IFU} / \mathrm{ml}$. (Immunotype $\mathrm{D}$ ), while no chlamydial organisms were recovered from baboon 1. Urethral specimens collected weekly for 2 months after inoculation and at 2 to 3 week intervals for a subsequent 5 months were consistently negative for Chlamydia.

The micro-IF antibody titres to Types ED before the second inoculation were $1: 128$ and $1: 16$ in baboons 1 and 2 , respectively. Antibody titres in both baboons continued to decrease after the second inoculation even in baboon 2, in whom transient shedding of chlamydial organisms was demonstrated by isolation. Antibody to Type I did not appear in baboon 1. 36 days after the second inocula- tion (and hence 155 days after primary inoculation) antibody in baboon 2 dropped below detectable levels (Table).

\section{Third inoculation}

7 months after the second inoculation (11 months after the first), a third intraurethral inoculation, similar to the second, was performed. Baboon 1 shed Type I chlamydial organisms from the urethra for 11 days in titres less than $1800 \mathrm{IFU} / \mathrm{ml}$., while baboon 2 shed Type D organisms for 14 days in titres less than $1500 \mathrm{IFU} / \mathrm{ml}$. Urethral specimens collected weekly for 2 more months were negative for chlamydial organisms.

Micro-IF antibody titre to Types ED was 1:32 in baboon 1 before the third inoculation. This titre did not rise, and antibody to type I did not develop after inoculation. Antibody in baboon 2 was completely absent before inoculation; 14 days after inoculation antibody to Types ED reappeared only to become undetectable again at 28 days (Table).

\section{Discussion}

This report confirms a preliminary observation of Darougar and others (1971) that chlamydial urethral infection can be experimentally induced in the male 
baboon and further characterizes the clinical, microbiological, and serological response to infection.

Both baboons shed chlamydial organisms from the urethra for about 3 months after the primary inoculation. The intensity of the infection appeared different in the two baboons. Although a truly quantitative assessment of Chlamydia in the urethra is not possible, a crude approximation may be gained by comparing the number of inclusion-forming units since the methodology was standardized. Although only two animals were used, a correlation was evident between IFU in urethral specimens, the serological response, and the occurrence of clinical signs. Urethral lesions were observed in conjunction with high titres of Chlamydia from the urethra and micro-IF antibody (baboon 1). The urethral lesions observed in baboon 1 may be unrelated to chlamydial infection although urethral follicles have been reported in the male baboon after inoculation of Chlamydia (Darougar and others, 1971). Clinically, there was no evidence of urethral discharge or pyuria, although the latter may have been missed since it was impossible to collect divided urine samples.

While only one urine sediment yielded chlamydial organisms, which suggests urinary infection, most were contaminated because of the difficulty of collecting specimens. Spontaneous recurrent shedding of Chlamydia independent of the inoculations was not demonstrated. The appearance of micro-IF antibody was delayed in comparison with the antibody response after chlamydial ocular infections in macaques (Wang and Grayston, 1971a).

Rechallenge 4 and 11 months after the first inoculation resulted in relatively shorter periods of infection of less than 15 days. These shorter periods of re-infection occurred in the absence of a humoral antibody response as antibody titres in both baboons remained essentially unchanged after re-inoculation. Immunity, as demonstrated by the short time that organisms were shed, is most likely cell-mediated. Furthermore, such immunity appears to be unrelated to immunotype, as the Type I infection in baboon 1 was similarly affected by the previous Type $D$ primary infection.

The antibody response, after primary infection, was variable in the two baboons, being of longer duration and higher titre in one than in the other. Subsequent infections were insufficient to boost the antibody titre. Additionally, heterologous infection, as with Type $I$ in baboon 1 , failed to alter the typespecific antibody pattern. In fact, antibody to Type I was not detected. Similar antibody responses may occur in humans after infection with Chlamydia (Wang and Grayston, 1974).

\section{Summary}

Two adult male baboons (Papio cynocephalus) were infected by urethral catheter with a Type D strain of Chlamydia trachomatis isolated from a male patient with nongonococcal urethritis. Chlamydial organisms were shed from the urethra for about 90 days and serum antibody developed. Intraurethral re-inoculation of homologous and heterologous (Type I) strains of Chlamydia, 4 and 11 months later, resulted in relatively shorter periods of infection of less than 15 days. The antibody titres and typespecific patterns were not substantially influenced by re-infection.

The authors are grateful for the excellent technical assistance of Cynthia Lee, Deanna Phinney, Patricia Skahen, and Mary Sundsmo.

\section{References}

Alexander, E. R., and Chiang, W. T. (1967) Amer. f. Ophthal., 63, 1145

Braley, A. E. (1939) Arch. Ophthal., 22, 393

Darougar, S., KINNISON, J. R., and JoNES, B. R. (1971) 'Chlamydial isolates from the rectum in association with chlamydial infection of the eye or genital tract. I. Laboratory aspects', in 'Trachoma and Related Disorders', ed. R. L. Nichols, p. 501. Excerpta Medica, Amsterdam

Dunlop, E. M. C., Al-Hussaini, M. K., Garland, J. A., Treharne, J. D., Harper, I. A., and Jones, B. R. (1965) Lancet, 1, 1125, 1286

-, Vaughan-Jackson, J. D., Darougar, S., and JONES, B. R. (1972) Brit. F. vener. Dis., 48, 425

Gordon, F. B., DRessler, H. R., QUAN, A. L., McQuillan, W. T., and Thomas, J. I. (1972) $A p p l$. Microbiol., 23, 123

Holmes, K. K., Handsfield, H. H., Wang, S.-P., Wentworth, B. B., TuRCK, M., ANDERSON, J. B., and AleXaNDER, E. R. (1975) New Engl. F. Med., 292, 1199

KING, A. (1970) Brit. med. f., 1, 451

OrIel, J. D., Reeve, P., Powis, P., Miller, A., and Nicol, C. S. (1972) Brit. F. vener. Dis., 48, 429

Pukhner, A. F., and KozLova, V. I. (1965) Akush. Ginekol., 41, 47

,-- (1967) Ibid., 43, 37

Richmond, S. J., Hilton, A. L., and ClaRke, S. K. R. (1972) Brit. F. vener. Dis., 48, 437

Smith, D. E., James, P. G., Schachter, J., Engleman, E. P., and MEYER, K. F. (1973) Arthr. and Rheum., 16, 21

Thygeson, P. (1934) Amer. F. Ophthal., 17, 1019

and Mengert, W. F. (1936) Arch. Ophthal., 15, 377

WANG, S.-P. (1971) 'A micro immunofluorescence method', in 'Trachoma and Related Disorders', ed. R. L. Nichols, p. 273. Excerpta Medica, Amsterdam

- and Grayston, J. T. (1971a) Idem, p. 217

- (1971b) Idem, p. 305

- - (1974) F. infect. Dis., 130, 388

Wentworth, B. B. (1973) Antimicrob. Agents Chemother., 3, 698

- and Alexander, E. R. (1974) Appl. Microbiol., 27, 912

WILlCox, R. R. (1972) Brit. F. vener. Dis., 48, 163 